Full length article

\title{
Current knowledge and future prospects of vaccines against cyprinid herpesvirus 3 (CyHV-3)
}

\author{
Maxime Boutier ${ }^{\mathrm{a}}$, Yuan Gao ${ }^{\mathrm{a}}$, Owen Donohoe ${ }^{\mathrm{a}, \mathrm{b}}$, Alain Vanderplasschen ${ }^{\mathrm{a}, *}$ \\ ${ }^{a}$ Department of Parasitic and Infectious Diseases, Faculty of Veterinary Medicine, University of Liège, Liège, Belgium \\ ${ }^{\mathrm{b}}$ Bioscience Research Institute, Athlone Institute of Technology, Athlone, Co Westmeath, Ireland
}

\section{A R T I C L E I N F O}

\section{Keywords:}

Cyprinid herpesvirus 3

koi herpesvirus

Common carp

Fish vaccine

Safety

Efficacy

\begin{abstract}
A B S T R A C T
Aquaculture is one of the world's most important and fastest growing food production sectors, with an average annual growth of 5.8\% during the period 2001-2016. Common carp (Cyprinus carpio) is one of the main aquatic species produced for human consumption and is the world's third most produced finfish. Koi carp, on the other hand, are grown as a popular ornamental fish. In the late 1990s, both of these sectors were threatened by the emergence of a deadly disease caused by cyprinid herpesvirus 3 (CyHV-3; initially called koi herpesvirus or KHV). Since then, several research groups have focused their work on developing methods to fight this disease. Despite increasing knowledge about the pathobiology of this virus, there are currently no efficient and costeffective therapeutic methods available to fight this disease. Facing the lack of efficient treatments, safe and efficacious prophylactic methods such as the use of vaccines represent the most promising approach to the control of this virus. The common carp production sector is not a heavily industrialized production sector and the fish produced have low individual value. Therefore, development of vaccine methods adapted to mass vaccination are more suitable. Multiple vaccine candidates against CyHV-3 have been developed and studied, including DNA, bacterial vector, inactivated, conventional attenuated and recombinant attenuated vaccines. However, there is currently only one vaccine commercially available in limited regions. The present review aims to summarize and evaluate the knowledge acquired from the study of these vaccines against CyHV-3 and provide discussion on future prospects.
\end{abstract}

\section{Introduction}

Aquaculture is one of the world's most important and fastest growing food production sectors, with an average annual growth of $5.8 \%$ during the period 2001-2016 [1]. Common carp (Cyprinus carpio) is one of the main aquatic species produced for human consumption. It is currently the world's 3rd most produced finfish, accounting for around $8 \%$ of the global production. As of 2016, annual production of common carp has reached 4.6 million tons [1]. Koi carp, on the other hand, are grown as a popular ornamental fish, kept in personal ponds by hobbyists, or sometimes submitted to koi competitions and exhibitions. In the late 1990 s, both of these sectors were threatened by the emergence of a deadly disease caused by cyprinid herpesvirus 3 (CyHV-3) (genus Cyprinivirus, family Alloherpesviridae, order Herpesvirales), initially called koi herpesvirus (KHV), or carp interstitial nephritis and gill necrosis virus (CNGV) [2-4]. Notably, the World Organisation for Animal Health (OIE) has listed CyHV-3 as a notifiable disease [5].
Since then, several research groups have focused their work on developing methods to fight this disease. One such method takes advantage of the fact that CyHV-3 replication and disease is strongly correlated with water temperature, with the disease occurring mainly at water temperatures between 18 and $28^{\circ} \mathrm{C}$ [2]. This observation has been exploited for the treatment of CyHV-3 infection by moving environmental temperatures at a suboptimal or non-permissive temperature for viral replication $\left(>30^{\circ} \mathrm{C}\right)$. This method was also used as a natural immunization method [6]. Unfortunately, fish infected through this approach were only partially protected against a subsequent challenge [6,7] and could potentially become latently infected by CyHV-3. Recently, fish infected by CyHV-3 have been shown to naturally seek out warmer environments which increases their ability to control CyHV-3 infection. This response to infection is known as behavioural fever [8]. This property could be exploited in aquaculture. Despite increasing knowledge about the pathobiology of this virus, there is currently no rational, efficient and cost-effective therapeutic methods

\footnotetext{
* Corresponding author. Immunology-Vaccinology lab, Faculty of Veterinary Medicine, University of Liège, Quartier Vallée 2, Avenue de Cureghem 10, 4000, Liège, Belgium.

E-mail address: a.vdplasschen@uliege.be (A. Vanderplasschen).
} 
available to fight this disease.

Facing the lack of efficient treatment, safe and efficacious prophylactic methods such as the use of vaccines represent the most promising approach in controlling this virus. In order to be feasible, vaccination of fish should ideally involve delivery methods adapted to the mass vaccination of the target species - thus minimizing the cost for vaccination. They should also stimulate long-lasting adaptive immunity, ideally over the entire lifetime of fish, and facilitate inoculation at earliest immunocompetent developmental stages. This is particularly true in the context of the common carp production sector that is not heavily industrialized and where fish produced have low individual value. Multiple vaccine candidates against CyHV-3 have been studied and currently only one is commercially available in a limited number of regions (Table 1). The present review aims to summarize the knowledge acquired from studies involving development of vaccines against CyHV-3. Future prospects on CyHV-3 vaccine are briefly discussed throughout the review and will be developed in the last section of this manuscript.

\section{Genomic and biologic comparison of CyHV-3 strains}

To date, the full-length genome sequences of 11 cell culture isolated CyHV-3 strains from different geographical origins have been published [9-11]. Genomic comparisons of these strains revealed a high level of similarity ( $>99 \%$ identity). This high degree of sequence similarity was confirmed by comparing full-length genome sequences of CyHV-3 obtained directly from infected fish tissues using targeted viral genomic enrichment [12]. Despite the high degree of genome sequence similarity, phylogenetic analysis of CyHV-3 full-length genome sequences revealed the existence of two major genetic lineages, initially named European and Asian [11]. Interestingly, analysis of one isolated strain (CyHV-3 GZ11), suggested the existence of a third, as of yet undetected, lineage, highlighting that future discoveries are likely regarding CyHV-3 diversity. Furthermore, the same study is the only example of comparative study of genomic and biological data from different CyHV-3 strains [11]. Importantly, the comparison of virulence among these strains lead to the identification of low, moderate and high virulence strains. Inter-lineage polymorphisms do not explain the differences of virulence observed, i.e. low and high virulence strains were found in both lineages [11]. Of note, a negative correlation was observed between the viral growth in vitro and the virulence in vivo inferring that, in general, the more adapted a viral strain is to cell culture, the more attenuated it is in vivo. This was the case for the highly cell cultureadapted CyHV-3 T strain [13]. The apparent low genomic diversity found among CyHV-3 strains can be considered as an advantage in terms of vaccine development. Indeed, cross protection following vaccination is expected but has not been studied, with the exception of a single report [14]. More importantly, the difference in virulence found among CyHV-3 strains, likely the consequence of cell culture, highlights the importance of selecting the correct strains for the development of vaccine. This selection applies at the beginning of the development when selecting the parental strain that will be used to produce the attenuated strain, and later when selecting a challenge strain to test the efficacy of the vaccine developed.

\section{Epidemiological status of CyHV-3}

There are limited published reports on the epidemiological data related to CyHV-3 prevalence and disease. Until now, CyHV-3 has been identified in at least 26 countries worldwide, including Israel, USA, China, Japan, and Indonesia [2]. CyHV-3 has not been reported in Africa (with the exception of South Africa), South America and Australia. Since its emergence in the late 1990s, CyHV-3 has caused mass outbreaks in carp in both natural environments and in fish farms. Initial outbreaks in Israel were responsible for annual losses estimated to US\$ 3 million [15]. Similarly, early outbreaks in Indonesia (2002, 2003) were held responsible for a global loss of US\$ 25 million [15]. Once 


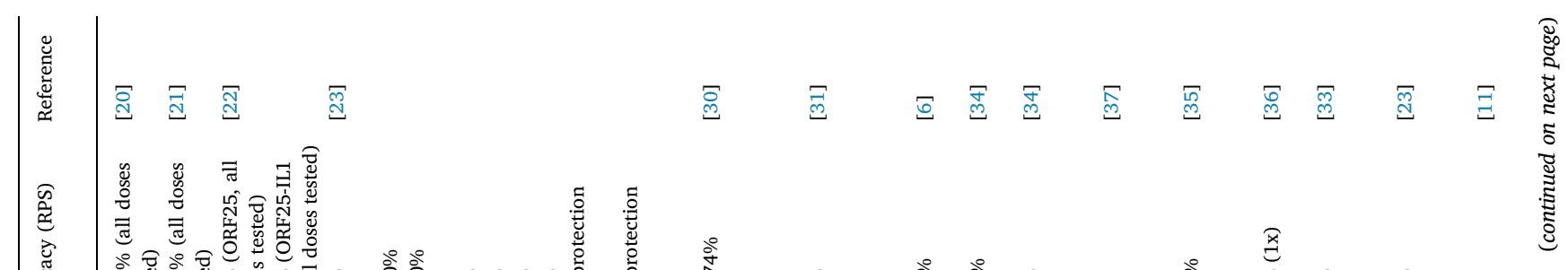

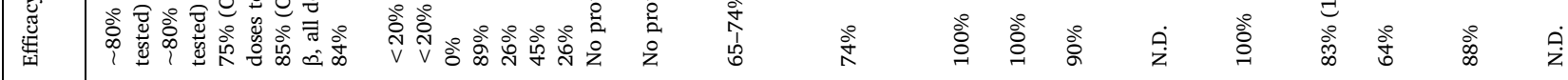

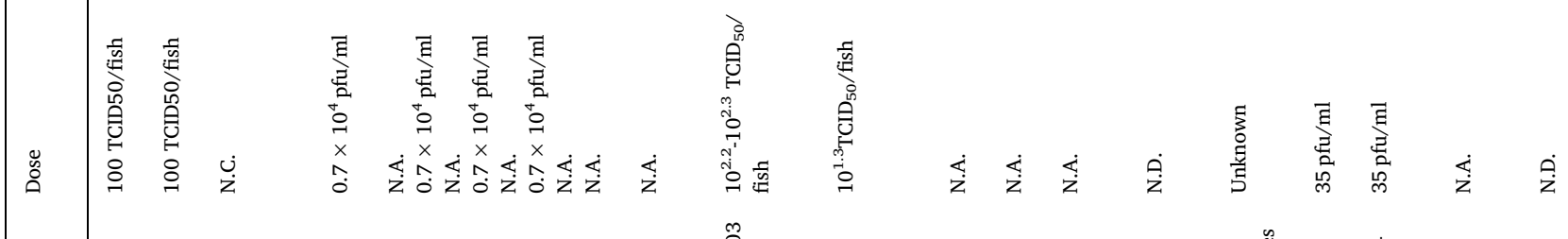

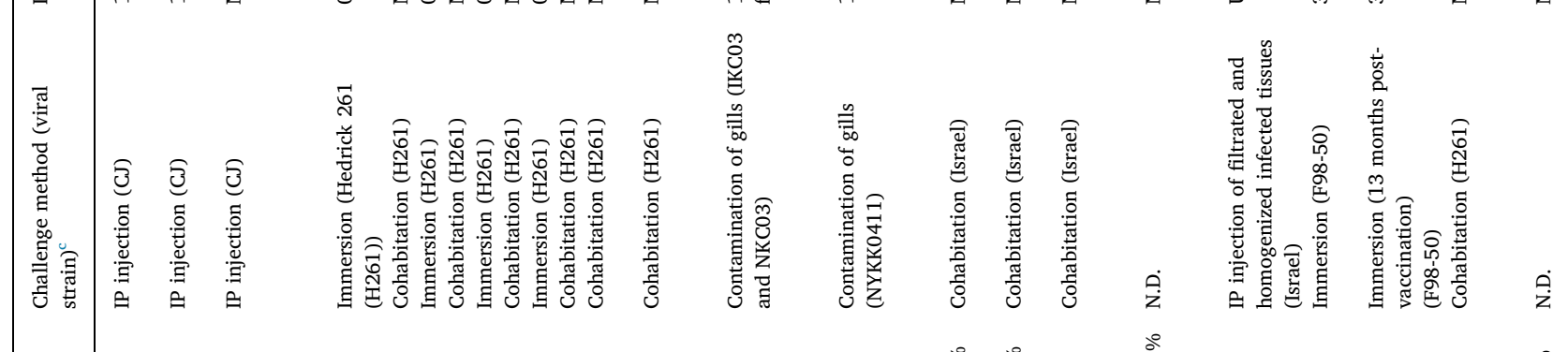

密

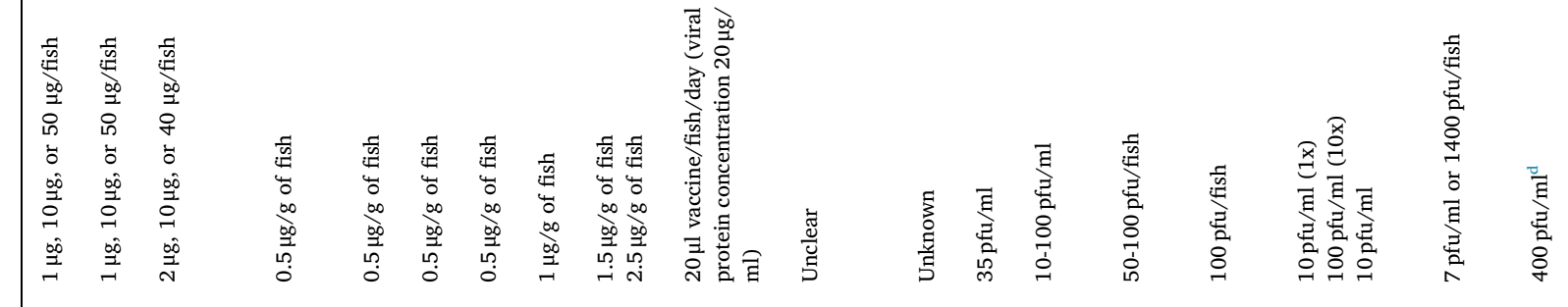

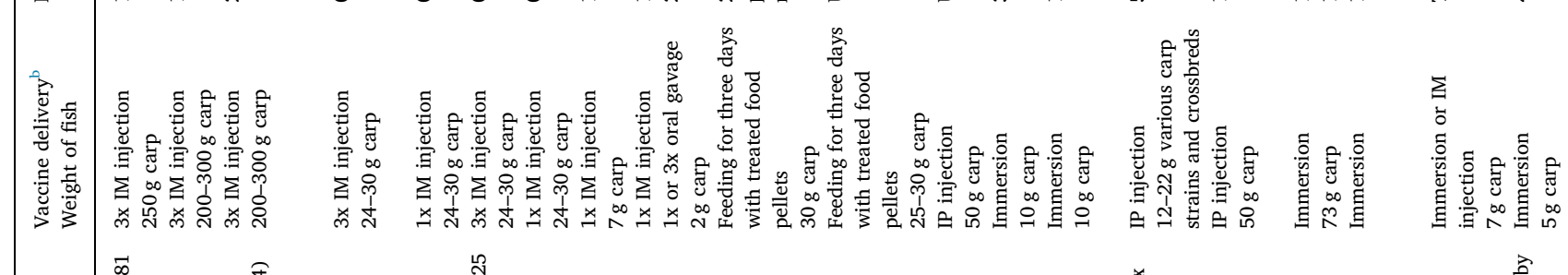

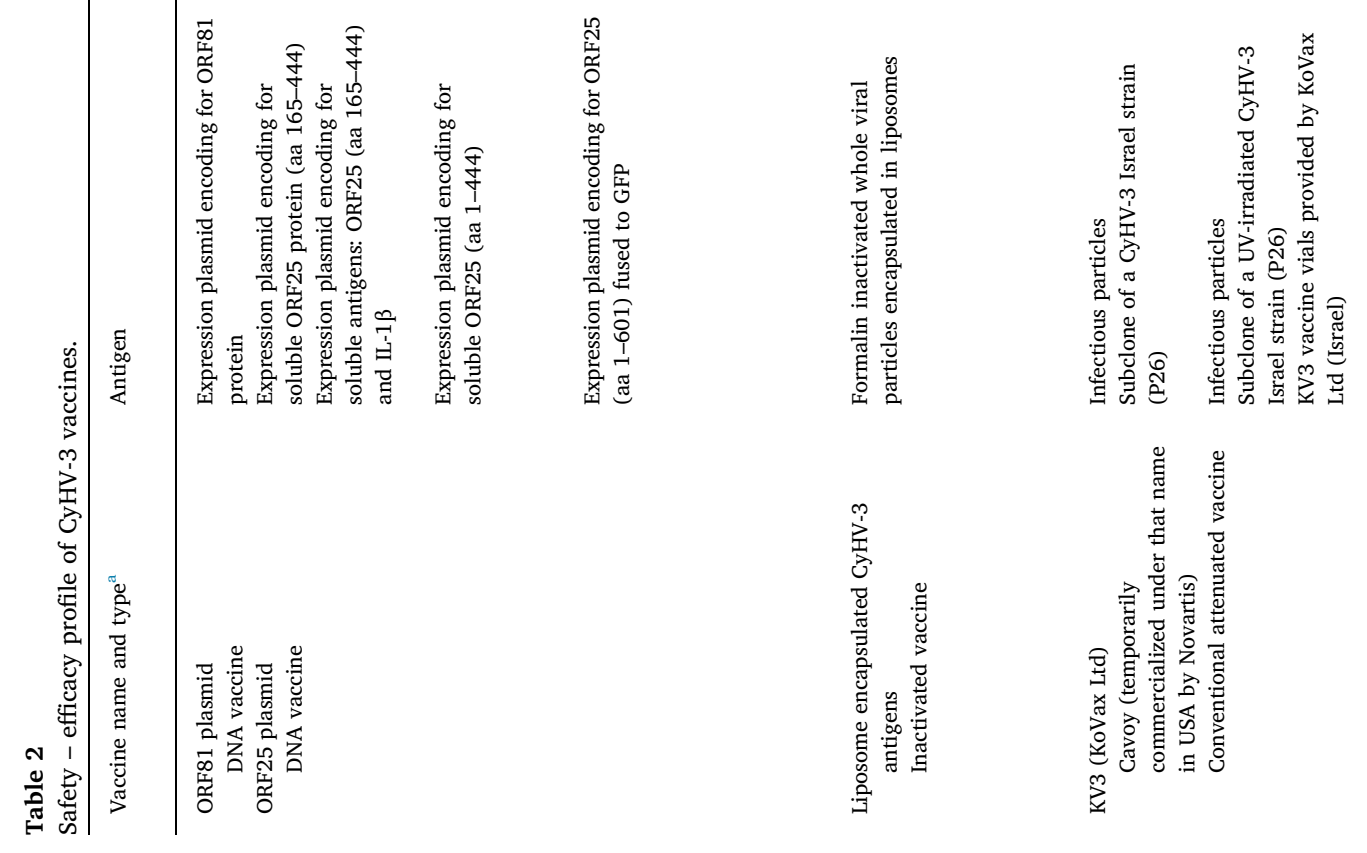

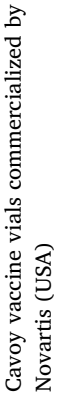


introduced into a specific environment, CyHV-3 can be maintained over consecutive seasons or years. This was demonstrated both in carp farms [16], but also in natural environment $[17,18]$. Nowadays, the exact epidemiological status and economical consequences of CyHV-3 infections and outbreaks are not clearly known and require further study.

\section{Types of vaccines studied}

\subsection{DNA vaccines}

DNA vaccines consist of genetically engineered DNA plasmids or fragments encoding for specific antigens from pathogens. They have different practical advantages, plasmid DNA vaccines are produced in prokaryotic cells, yielding large amounts of highly pure and stable DNA. However, DNA vaccines usually require injections into the fish in order to achieve adequate immune protection, although the oral route has been successfully used in few trials [19]. In terms of CyHV-3 DNA vaccines, early reports have investigated the potential use of expression plasmids encoding ORF81 and ORF25 glycoproteins (a major envelope protein, and a member of the ORF25 glycoprotein family, respectively). In these trials, three successive injections of different doses of DNA ( $1 \mu \mathrm{g}, 10 \mu \mathrm{g}$ and $50 \mu \mathrm{g}$ per $250 \mathrm{~g}$ carp) led to a serological response and immune protection (Relative Percent Survival (RPS) of around $80 \%$ ) (Table 2) [20,21]. Similarly, the CyHV-3 glycoprotein ORF25 was tested in combination with the carp interleukin-1 $\beta$ (IL-1 $\beta$ ) cytokine gene as a prototypic adjuvanted DNA vaccine. Following inoculation, it was found that, while the co-expression of IL-1 $\beta$ can enhance the serological immune response, it had no statistically significant effect on the protection observed (RPS of $85 \%$ and $75 \%$, with or without the IL-1 $\beta$ adjuvant, respectively) [22]. Very recently, another study has investigated the practical use of an ORF25 DNA vaccine with the aim of optimizing vaccine delivery through the oral route. Surprisingly, they found that intra-muscular (IM) injection of the CyHV-3 ORF25 DNA construct (fused with the green fluorescent protein (GFP)) protects fish against a lethal challenge by immersion, but not by cohabitation (RPS $89 \%$ against $26 \%$, respectively) [23]. This result highlights the importance of using relevant challenge methods for assessing vaccine efficacy. Notably previous reports on the ORF25/ORF81 DNA vaccine investigated the immune protection by using intra-peritoneal (IP) challenges [20-22]. It was also confirmed that three IM injections are necessary to ensure significant immune protection and that oral delivery of alginate-encapsulated plasmid DNA was not efficacious [23]. Although the ORF25 DNA vaccine strategy is tempting and sometimes promising, the results obtained in the literature are conflicting. The discrepancies observed between studies might be partially explained by differences in the portions of the ORF25 protein used for immunization (Table 2). In any case, the current method of vaccination (three successive IM injections) does not facilitate ease of application in the field. Furthermore, due to the complexity and high number of glycoproteins present in the CyHV-3 proteome [24], a single antigenic protein gene used as a DNA vaccine might not be enough for efficient protection through different challenge models [23].

\subsection{Bacterial vector vaccines}

Facing the technical challenges involved with development and delivering of effective DNA (or subunit) vaccines, some studies have investigated the potential use of bacteria as vectors for expression of CyHV-3 antigens. Such bacterial vector vaccines, expressing viral antigens are easily adaptable to large-scale production, and represent efficient delivery methods. Indeed, many bacterial vaccines can be adapted to mass vaccination including immersion and sometimes oral methods. The use of Lactobacillus plantarum expressing CyHV-3 ORF81 (major envelope protein) fused to the glycoprotein $\mathrm{G}(\mathrm{gG})$ of spring viremia of carp virus (SVCV, genus Sprivivirus, family Rhabdoviridae) has been reported [25]. The bacteria were mixed at a ratio of $10^{9} \mathrm{cfu}$ 
per gram of fish feed. Fish were fed with the vaccine preparation during three successive days, and for three distinct vaccination periods (a primary vaccination and two subsequent boosts). Fish were then challenged by oral administration of either SVCV or CyHV-3. Treated fish developed specific antibodies against both viruses and were partially resistant to a lethal challenge. Surprisingly, the serological and survival data were strikingly similar following the two viral species challenges (RPS of 63 and $45 \%$ for SVCV and CyHV-3 respectively). Also, in a recent study, the $\mathrm{N}$-terminal (aa 42-149) cysteine-free domain of CyHV-3 ORF149 (a member of the CyHV-3 ORF25 glycoprotein family), containing immuno-relevant epitopes [26] was fused to several bacterial anchor-motifs. These motifs allowed expression of the viral antigen at the outer bacterial membrane. The plasmid constructs were transformed into Escherichia coli BL21 and the recombinant bacteria were used as inactivated bacterial suspensions. The inactivated bacterial preparations were delivered by immersion preceded by an unconventional low-intensity ultrasound treatment [27]. A serological response was not observed in all of the common carp and zebrafish (Danio rerio) vaccinated by this method and unfortunately, the level of protection against a lethal challenge was not investigated in this study [27]. However, though still in its infancy, this method represents a putative promising way to improve CyHV-3 vaccine strategies.

\subsection{Inactivated vaccines}

Inactivated vaccines consist of the entire pathogen of interest, killed or inactivated, typically using chemical or physical methods [28]. Due to their inability to replicate in the host, inactivated vaccines are generally considered safer, but at the same time, less immunogenic than live-attenuated vaccines. In aquaculture, inactivated viral vaccines usually require multiple injections of a high dose of antigens combined with adjuvants, implying a low cost-benefit balance [29]. Few studies have investigated the potential use of inactivated vaccines against CyHV-3. In one such study, formalin-inactivated CyHV-3 viral particles were trapped within a liposomal compartment and spread onto dry food pellets. Administered by ingestion, they induced partial immune protection against a lethal challenge (RPS around 70\%) (Table 2) [30]. Another report employing similar methodology with a different CyHV-3 isolate was able to induce similar protection [31].

In another report, three adjuvanted (Montanide ISA 763 A VG) and inactivated CyHV-3 antigen preparations were tested as vaccine candidates, however they showed very limited protection against subsequent viral challenge. This may have been caused by incomplete presentation of viral antigens, with the administered vaccine persisting as intact droplets within the abdominal cavity after injection [32].

\subsection{Attenuated vaccines}

Attenuated vaccines are live viral strains for which the virulence has been reduced or abolished by serial passages in cell culture (conventional attenuated vaccine) or by targeted viral genome editing (recombinant attenuated vaccines). Unlike inactivated, subunit, vector or DNA vaccines, attenuated vaccines are highly representative of a natural viral infection in the host. Because of this, they are usually effective after a single dose administration, and they facilitate much broader stimulation of the immune system during vaccination, resulting in both cell-mediated and humoral adaptive immune responses and increased long-term protection against viral disease. As they usually retain their natural ability to enter the host without the need of specialized delivery methods, such vaccine strains should be largely compatible with mass vaccination in an aquaculture setting (i.e. inoculation of large numbers of fish via bathing). Given their superior efficacy, historically, attenuated viral vaccines have arguably been the most important and effective intervention method against the spread of viral disease. However, given their nature, these vaccines also raise safety concerns, such as residual virulence, reversion to virulence, and unregulated spread from vaccinated to naïve subjects.

\subsubsection{Conventional attenuated vaccines}

A conventional attenuated vaccine has been developed against CyHV-3 [6,33-36]. KoVax Ltd (Israel) initially developed and commercialized the CyHV-3 conventional attenuated vaccine under the denomination of KV3. The KV3 vaccine was also temporarily launched in the US market by Novartis under the denomination of Cavoy.

The development of this vaccine went through different successive processes. First, a CyHV-3 Israel strain was serially passed in koi fin cells ( $>20$ passages), leading to partial attenuation of the virus [6]. Second, the viral suspension obtained by serial passages was subcloned and tested in vivo, leading to the selection a specific subclone [6,34]. Finally, the selected subclone was further treated by UV irradiation preceding a second and ultimate subcloning step [34]. The main goal of these different procedures was to (i) to limit the risk of recombination between variants present in the viral suspension (achieved through subcloning) and (ii) increase the number of mutations introduced in the viral genome and therefore decrease the risk of reversion to a virulent phenotype (achieved through serial passages and UV irradiation). This vaccine has been tested using several delivery methods that have been shown to provide protection against a lethal challenge. Importantly, the current commercialized KV3 vaccine was designed for delivery via simple immersion of koi and common carp in water containing the attenuated strain, thereby allowing mass vaccination.

The safety and efficacy profile of this conventional attenuated vaccine was studied extensively [6,11,15,23,33-37]. Regarding the safety, several independent trials showed residual virulence in some circumstances. For instance, the vaccination of small-sized fish $(<50 \mathrm{~g})$ can be associated with clinical signs of the CyHV-3 disease and mortalities (10-30\% according to the studies, Table 2) [11,35-37]. Furthermore, some mortalities were specifically associated with certain carp strains [37] or were attributed to a bad health status of the fish used [35]. Notably, recurrent detection of CyHV-3 DNA was observed in fish that survived or died from the vaccination [36]. Nevertheless, field trials were successfully conducted for regulatory purposes in Israel, Indonesia and USA. They indicated that this attenuated strain met the requirements necessary for registration of the vaccine in these regions [15].

A second important issue associated with this vaccine is the unknown determinism of the attenuation. It makes it difficult to determine the likelihood of reversion to a virulent phenotype [15,38]. Sequencing revealed several mutations (including large insertions and deletions (indels)) throughout the viral genome [11], but the exact role of these mutations in the attenuation is completely unknown. If the attenuation is caused by single nucleotide polymorphisms, these mutations are the most at risk of reversion during vaccine infections, with resulting revertant viral strains having a competitive advantage. However, backpassage assays, during which the vaccine strain is recovered from vaccinated animals and administered to naïve animals successively, did not show any reversion to virulence [15].

Ecological safety concerns can also be raised when registering live attenuated vaccines [15]. Indeed, the attenuated vaccine could cause disease by transmission to fish species which are not the primary target of the vaccination. Despite the fact that CyHV-3 DNA can be detected in a variety of fish species (reviewed by Ref. [2]), disease is only diagnosed in common and koi carp and related hybrids [39]. Nevertheless, the susceptibility of additional fish species to CyHV-3 is still highly controversial $[40,41]$. However, the possibility that the attenuated vaccine strain may infect cohabitant common carp not primarily targeted by the vaccination has been investigated [36]. In terms of horizontal transmission of the vaccine strain, no death or signs of disease were observed in naïve carp cohabited with vaccinated carp at four weeks post-vaccination. However, unfortunately, quantitative PCR analysis could not be interpreted confidently due to positive results obtained in the negative control groups [36]. To the best of our 
knowledge, the ability of the conventional attenuated vaccine to establish latency and to reactivate have not been demonstrated. Latency associated with abortive reactivation (without excretion of infectious particles) could act as periodical boosts of the adaptive immune response providing lifelong protection to vaccinated subjects. However, latency associated with successful reactivation (with excretion of infectious particles) could be associated with uncontrolled spreading of the vaccine strain and could enhance the occurrence of recombination between the vaccine strain and field strains.

Regarding the efficacy, the attenuated vaccine has shown satisfying results, inducing RPS ranging from 80 to $100 \%$. Importantly, in these experiments, fish were challenged by cohabitation with sick fish in several studies, which represents a highly relevant challenge method. Following vaccination, detection of anti-CyHV-3 antibodies started between 7 and 14 days post-infection (dpi), and increased until 20-40 dpi and finally progressively decreased with significant titers still detected at 150 dpi $[6,35]$. During these periods, the anti-CyHV-3 antibody response correlated with protection against CyHV-3 disease. On the other hand, at $280 \mathrm{dpi}$, the titer of anti-CyHV-3 antibodies in previously vaccinated fish was only slightly higher or comparable to that of naive fish. Nevertheless, immunized fish, even those in which antibodies were no longer detectable, were resistant to a lethal challenge, possibly because of the subsequent rapid response of $\mathrm{B}$ and $\mathrm{T}$ memory cells to antigen re-stimulation [35]. Similarly, anti-CyHV-3 antibodies were detected in only $14 \%$ of the vaccinated fish 13 months post-vaccination, however this was associated with only a partial protection against a lethal challenge, supporting the need of annual booster vaccination [33]. Indeed, following booster vaccination performed 6 months after initial exposure to the attenuated vaccine, antibody titers increased again [35].

\subsubsection{Recombinant attenuated vaccines}

Due to scientific advances in molecular biology and molecular virology, the development of attenuated vaccines is evolving away from the historical empirical approaches and towards rational design. Using this approach, a viral genome can be edited to delete genes encoding virulence factors in such a way that reversion to virulence can be excluded.

The initial cloning of the CyHV-3 genome as infectious bacterial artificial chromosome (BAC) facilitated viral editing using prokaryotic mutagenesis methods [42]. This is referred to as BAC cloning and the main advantage of this approach, over viral editing using homologous recombination in eukaryotic cells, is the high stability of the viral genome throughout the process. This method, combined with the advances in DNA sequencing, allows rapid generation, characterization and comparison of viral recombinants mutated only for the desired ORFs.

Recombinant CyHV-3 attenuated vaccine candidates have been generated by targeting different genes thought to encode virulence factors. Initially, several studies investigated the potential use of viral recombinants deleted for genes encoding for enzymes of the nucleotide metabolism (ORF55 encoding for a thymidine kinase (TK), ORF123 encoding a deoxyuridine triphosphatase (dUTPase), and ORF141 encoding for the large subunit of the ribonuleotide reductase (RNR)). Deletion of the RNR ORF141 gene led to a drastic reduction of viral growth in vitro. Truncation of the TK ORF55 was initially found to partially attenuate the virulence [42], but the attenuation was weak and not reproducible between trials $[43,44]$. Similarly, the ORF123 dUTPase deletion is associated with partial attenuation. Recently, using an eukaryotic recombination based approach, a double deletion of both ORF55 TK and ORF123 dUTPase has been described in two independent viral strains (CyHV-3 I, low cell culture adaptation/high virulence profile [45]; and CyHV-3 T, high cell culture adaptation/low virulence profile $[11,13]$ ) [46]. In both cases, an important attenuation was observed, and significant protection was ensured following a lethal challenge with the parental strain (Table 2) [46]. The use of the CyHV-3
$\mathrm{T}$ viral strain has two main advantages (i) an attenuated genetic background, possibly due to serial passages in cell culture and (ii) an efficient viral growth in vitro ensuring a good vaccine production. However two disadvantages of this design include (i) the CyHV-3 T determinism of attenuation is unknown and (ii) multiple and distant deletions increase the risk of emergence of single deleted recombinants for either of the two ORFs following recombination with wild type strains. These recombinants carrying one of the two genetic traits of the vaccine should benefit from a partial gain of virulence. Their possible spread from vaccinated subjects to cohabitants could be confused with vaccine spread unless the follow-up will be based on the study of both deleted loci.

The prokaryotic approach described earlier was also used to target and remove CyHV-3 envelope glycoproteins [24]. The 16 predicted virion transmembrane proteins (VTPs) were deleted by using the BAC cloning mutagenesis technology. Individual deletion of 8 VTPs encoding ORFs was compatible with viral growth. Among them, only deletions of ORF148 and ORF25 (both members of the ORF25 family), were associated with slight or severe attenuation, respectively. Unfortunately, deletion of ORF25 was safe but not efficacious in protecting fish against a lethal challenge (maximum RPS of 34\%) [24]. Similarly, another study investigated the single deletion of ORF148 or ORF149, and the combinational deletion of both [47]. Again, the attenuation obtained was only partial with approximately $50 \%$ and $40 \%$ reduction of the virulence observed for single and double deleted mutants respectively compared to the parental strain (CyHV-3 T) [47]. ORF25, ORF148 and ORF149 (together with ORF27, ORF65 and the pseudogene ORF26) are members of the ORF25 family, all encoding VTPs. While studies such as the ones described earlier indicate that the deletion of these genes can cause attenuation, it should be acknowledged that recombinants displaying single (or even double) deletions for members of this glycoprotein family are always open to the risk of reversion to virulence through mutation of the remaining paralogous genes, making them less suitable vaccine candidates.

In another series of studies, a vaccine candidate was produced by taking advantage of an accidental double deletion of ORF56 and ORF57 obtained following a non-homologous recombination event [43]. The ORF56-57 deletion ( $\Delta 56-57)$ was replicated in several independent recombinants, using BAC cloning mutagenesis (CyHV-3 FL viral strain). They were all compatible with its use as an attenuated recombinant vaccine for mass vaccination of carp by immersion in water containing the virus. Indeed, vaccination of common carp with the $\Delta 56-57$ strain was particularly safe and induced high protection against a lethal cohabitation challenge. The safety was demonstrated for young and smallsized fish (mean weight of $1.3 \mathrm{~g} ; 4$ months old) [43]. Importantly, the immune protection was similar against a homologous (CyHV-3 FL strain, moderate virulence, European lineage) and heterologous challenge (CyHV-3 M3 strain, high virulence, Asian lineage) (Table 2) $[11,14,43]$. Interestingly, the safety and efficacy investigations of this vaccine candidate were not limited to the clinical outcome of the disease. Regarding the safety, the $\Delta 56-57$ locus was combined with a luciferase (Luc) expression cassette described previously [48], forming the $\Delta 56-57$ Luc viral recombinant [43]. This was exploited to investigate the vaccine tropism and transmission using In Vivo Bioluminescent Imaging System (IVIS). The results obtained showed that the vaccine candidate replicated at the skin portal of entry for 8 days following vaccination, suggesting good immune stimulation at the skin mucosa. In the secondary sites of infections, the vaccine replication was delayed, of lower intensity, and present for a shorter duration compared to the wild type infection. Histopathological analyses of the gills showed minimal lesions induced by the vaccine and a complete midterm histological recovery. Regarding transmission, vaccinated fish were cohabited (allowing direct or indirect transmission) with naïve sentinel fish immediately following vaccination, i.e. to maximise the chances of transmission. Indirect transmission of the vaccine strain was not observed (i.e. through infectious water), while a limited and erratic 
transmission was observed when vaccinated and sentinel fish were mixed together in the same tank allowing transmission through infectious water and through fish skin-to-skin contacts. Although the ability of the $\Delta 56-57$ vaccine to establish latency and reactivation is unknown, its limited replication and transmission during the acute infection of naïve subjects makes it unlikely that it will efficiently replicate in an immunized subject following a hypothetical reactivation event. Finally, the protective immune response following vaccination was shown to block the challenge viral infection at the skin portal of entry [43]. Whether this protection is the consequence of a mucosal adaptive immune response or not remains to be determined. This homologous virus/fish model represents a unique opportunity to study fish mucosal immunity in the context of vaccination. Recently, ORF57 was found to be the crucial virulence factor in the double deletion of ORF56 and ORF57. The function of ORF57 remains to be determined, but ORF57 protein is an abundant component of the virion structural proteome $[24,49]$. Interestingly, this opens the opportunity to use this vaccine as a DIVA strategy (Differentiating Infected from Vaccinated Animals), on the basis that an adaptive serological immune response could be raised against ORF57 protein following a wild type infection, but not after vaccination. The immunogenicity of ORF57 protein, but also of dUTPase and TK proteins described above, are currently unknown. Also, a monoclonal antibody raised against ORF57 protein is already available, allowing the differentiation between the vaccine strain and the wild type strains [14]. Finally, the identification of ORF57 as a crucial virulence factor of CyHV-3 opens new vaccine research opportunities, as ORF57 homologs represent evident targets for further development of attenuated recombinant vaccines for other pathogenic viruses (CyHV-1, CyHV-2 and anguillid herpesvirus 1 (AngHV-1); all members of the genus Cyprinivirus, family Alloherpesviridae) [14].

\section{Knowledge gained from vaccine studies on other alloherpesviruses}

The family Alloherpesviridae consists of a growing list of alloherpesviruses infecting fish and amphibians. It contains four genera with 13 virus species currently recognised by the International Committee on Taxonomy of Viruses (ICTV). Multiple vaccine candidates against alloherpesviruses have been developed but very few are currently commercially available. Inactivated vaccine candidates against CyHV-2 (a virus phylogenetically close to CyHV-3) have been explored. These include formalin- or beta-propiolactone- inactivated CyHV-2 preparations which were injected IP to goldfish (Carassius auratus) or gibel carp (Carassius gibelio), respectively and induced partial protection against a lethal challenge (RPS $42-63 \%$ and $71 \%$, respectively) [50,51]. The results obtained for this CyHV-2 inactivated vaccine are promising in terms of safety/efficacy balance. Nevertheless, this vaccination method still suffers several drawbacks: (i) the high volume of crude supernatant needed to vaccinate each fish, (ii) the necessity to individually handle and inject the fish and (iii) the relative low immune protection obtained even when boosting strategies were applied [50,51]. Subunit vaccines consist of a reduced and specifically selected portion of the virus antigen repertoire. Subunit vaccines against CyHV-2 have been tested in gibel carp. This involved immunization with secreted forms of the ORF25, ORF25C and ORF25D antigens (CyHV-2 ORF25 glycoprotein family) purified from yeast ( $P i-$ chia pastoris). This led to partial protection (RPS: 54\%-75\%) [52]. This method has the added advantage of being compatible with mass and low cost production of the antigen of interest through purification from the supernatant of cultivated yeasts [52].

Some DNA vaccines against Ictalurid herpesvirus 1 (IcHV-1, also known as channel catfish virus or CCV, genus Ictalurivirus) have also been tested. Injectable DNA vaccines against IcHV-1 showed ambiguous results, even when a cocktail of plasmids encoding multiple ORFs were used [53,54]. Vaccination with plasmids encoding ORF6, ORF59 (encoding for a membrane protein and a VTP respectively) or the combination of both, induced significant protection against IcHV-1 challenge [53], but that result was not reproduced elsewhere [54]. DNA immunization with ORF1, ORF3 (encoding immediate-early unknown proteins), ORF7, ORF8, ORF10, ORF19, ORF46, ORF51 (encoding membrane proteins) and ORF53 (encoding capsid proteins) did not induce immune protection against a lethal challenge [53,54]. Importantly, cocktails of up to 11 DNA plasmids ( $1 \mu \mathrm{g} / \mathrm{plasmid})$ did not enhance immune protection. Along with other studies on the use of DNA vaccines against other alloherpesviruses, this highlights the fact that selecting the most relevant antigens for immunization is one of the main challenges for future research.

Conventional and recombinant attenuated vaccines have also been developed against IcHV-1. A conventional attenuated vaccine was generated through serial passage of the Auburn IcHV-1 strain on a walking catfish cell line (Clarias Batrachus) [55]. The parental strain, that had a history of 35 passages, was further passed 60 times in cell culture (from then referred to as the V60 strain). A dose-effect study showed a high safety of the attenuated strain following IP injection with up to $1 \times 10^{5}$ TCID50 per fish. The definitive cause of attenuation of the V60 strain is still unknown, despite the fact that a deletion of ORF50 (encoding a putative secreted glycoprotein) was detected [56]. A recombinant attenuated vaccine candidate was also developed against IcHV-1 by deletion of the TK gene (ORF5) which resulted in a 100 fold decrease in virulence. Vaccination by immersion with this vaccine candidate at the doses of $3 \times 10^{4}$ and $3 \times 10^{5}$ had a safety/efficacy profile of $0 / 60 \%$ and $5 / 100 \%$, respectively [57]. Deletion of TK from different alloherpesvirus models seems to be definitely associated with attenuation in some conditions [42,46,57]. On the other hand, some discrepancies were observed between trials $[43,44]$ and single deletion of the TK was not always sufficient to induce attenuation of the virus [47]. TK deletion is thought to mainly affect the replication of the virus in non-replicating cells that do not provide endogenous expression of cellular TK (a cellular enzyme expressed during the $S$ phase of the cell cycle). However, infection of fish in their fast growth phase could express high level of cellular TK in replicating cells, thereby facilitating the complementation of the TK viral defect $[42,57]$. This suggests that the effect of TK deletion on viral replication could be dependent of the physiology of the host with attenuation being observed mainly in fish with reduced cell division. Taking into account that small fish associated with a high proportion of dividing cells are those to be vaccinated, deletion of TK does not appear to be a good gene candidate for virus attenuation.

Huge improvements in molecular techniques and viral genome manipulation created opportunities to develop viral vectors that act as expression platforms for antigens from other pathogens. Preliminary results obtained from inoculating fish with a TK deleted, IcHV-1 attenuated vaccine expressing a recombinant LacZ reporter gene showed that immunized fish expressed the LacZ reporter and indeed developed an antibody response against the transgene. Interestingly, this serological adaptive immune response could be boosted 20 days postvaccination. The previous cloning of IcHV-1 as an infectious bacterial artificial chromosome [58] allows manipulation of this vial genome in a similar manner to CyHV-3 [42], and thus is a crucial tool in the development of future innovative vaccines against IcHV-1.

\section{Future prospects for CyHV-3 vaccine development}

Ongoing advances in our understanding of fish immunology and constant progression in vaccine technology will continue to play a role in shaping the future of CyHV-3 vaccine development. As with all vaccines, there will continue to be a drive to develop vaccines with superior safety/efficacy profiles and improved delivery methods. Furthermore, vaccines for fish, and other animals in the food production sector in general, are under additional constraints in order to maximise their use in the field. Firstly, ideally the vaccine must be compatible with mass vaccination. Secondly, the cost-benefit ratio 
Table 3

Advantages and disadvantages of various vaccines against CyHV-3.

\begin{tabular}{|c|c|c|c|}
\hline Vaccine $^{\mathrm{a}}$ & Vaccine type & Advantages & Disadvantages \\
\hline $\begin{array}{l}\text { ORF25 (ORF81) plasmid- based } \\
\text { vaccines }\end{array}$ & DNA vaccine & $\begin{array}{l}\text { - Non-infectious: high safety } \\
\text { - Easy to produce in prokaryotic cells } \\
\text { - ORF25 glycoprotein is a major antigen } \\
\text { - DIVA }\end{array}$ & $\begin{array}{l}\text { - Conflicting results of efficacy between independent } \\
\text { studies } \\
\text { - Requires multiple IM injection to be efficacious } \\
\text { - Risk of integration into the host genome } \\
\text { - Exposure to only specific antigen }\end{array}$ \\
\hline $\begin{array}{l}\text { Liposome encapsulated CyHV-3 } \\
\text { antigens }\end{array}$ & Inactivated vaccine & $\begin{array}{l}\text { - Non-infectious } \\
\text { - Compatible with oral vaccination } \\
\text { - Contains all CyHV-3 antigens }\end{array}$ & $\begin{array}{l}\text { - Risks associated with inefficient inactivation } \\
\text { - Partial protection observed against a lethal challenge } \\
\text { - Requires complex lab procedures and high amounts of viral } \\
\text { antigen }\end{array}$ \\
\hline KV3 (KoVax Ltd) & $\begin{array}{l}\text { Conventional attenuated } \\
\text { vaccine }\end{array}$ & $\begin{array}{l}\text { - Vaccine mimicking a natural infection } \\
\text { - Safety/efficacy profile favorable, but not } \\
\text { optimal } \\
\text { - Compatible with mass vaccination } \\
\text { - Differentiation of vaccine and wild type strains } \\
\text { based on analysis of indels }\end{array}$ & $\begin{array}{l}\text { - Residual virulence for small-sized fish } \\
\text { - Determinism of attenuation unidentified } \\
\text { - Risk of reversion to virulence } \\
\text { - Requires environmental temperatures compatible with } \\
\text { vaccine replication }\end{array}$ \\
\hline CyHV-3-T $\Delta$ DUT/TK & $\begin{array}{l}\text { Recombinant attenuated } \\
\text { vaccine }\end{array}$ & $\begin{array}{l}\text { - Vaccine mimicking a natural infection } \\
\text { - Good safety/efficacy profile } \\
\text { - Compatible with mass vaccination } \\
\text { - Limited risk of reversion to virulence } \\
\text { - DIVA based on deleted gene (genetically, } \\
\text { antigenically and hypothetically based on } \\
\text { serology) }\end{array}$ & $\begin{array}{l}\text { - Requires environmental temperatures compatible with } \\
\text { vaccine replication } \\
\text { - Risk of recombination in between the two genomically } \\
\text { distant deletions, thereby producing single deleted } \\
\text { recombinants } \\
\text { - Considered as a genetically modified organism by } \\
\text { regulation authorities }\end{array}$ \\
\hline CyHV-3-FL $\Delta 56-57$ & $\begin{array}{l}\text { Recombinant attenuated } \\
\text { vaccine }\end{array}$ & $\begin{array}{l}\text { - Vaccine mimicking a natural infection } \\
\text { - Good safety (including reduced spreading)/ } \\
\text { efficacy profile } \\
\text { - Compatible with mass vaccination } \\
\text { - Limited risk of reversion to virulence } \\
\text { - DIVA based on deleted gene (genetically, } \\
\text { antigenically and hypothetically based on } \\
\text { serology) }\end{array}$ & $\begin{array}{l}\text { - Requires environmental temperatures compatible with } \\
\text { vaccine replication } \\
\text { - Considered as a genetically modified organism by } \\
\text { regulation authorities }\end{array}$ \\
\hline
\end{tabular}

a Only vaccines (or candidate vaccines) displaying a promising safety/efficacy profile are shown in this table.

should be as low as possible, implying the lowest cost for vaccine production and administration per individual. Thirdly, the use of any such vaccine should be safe and result in close to $100 \%$ RPS. These constraints will continue to represent the benchmark in determining whether or not future vaccine approaches may be considered viable options. In terms of CyHV-3, with the exception of attenuated vaccines, no approach to vaccination against this virus has met all of the constraints described above, these shortfalls and future prospects for further development are discussed in the following section. A summary of the main advantages and disadvantages of some vaccines against CyHV-3 is provided in Table 3.

\subsection{Future prospects on $\mathrm{CyHV-3}$ vaccines based on selected antigens}

\subsubsection{DNA vaccines}

While some DNA vaccine-based approaches have shown promise [20-22], these involved delivery through IM injection, which is not suitable to mass vaccination of small-sized common carp. This may be more suitable to individual vaccination of koi carp, however the risk of injury to extremely valuable subjects may somewhat limit its use in this niche sector. The development and refinement of oral or immersionbased delivery methods may improve the future prospects of DNA vaccines against CyHV-3 compatible with mass vaccination. While encapsulation of CyHV-3 DNA vaccine in alginate for the purposes of oral delivery did not yield promising results [23], other DNA vaccine encapsulation methods may prove useful in facilitating successful oral delivery. Examples of alternative encapsulation methods for oral delivery include the use of chitosan-based nanoparticles, which have shown promise with DNA vaccines against sea bass nodavirus [59]. In addition, encapsulation or surface adsorption of DNA vaccines to poly(D,L-lactic-co-glycolic)-acid (PLGA) particles may also be potentially useful for these purposes, if adapted appropriately $[19,59,60]$. If such approaches could be used in oral delivery with similar or greater protection than injection, it may make CyHV-3 DNA vaccines more compatible with mass vaccination.

\subsubsection{Bacterial vector vaccine}

The CyHV-3 bacterial vector vaccines are, by their nature, compatible with mass vaccination, being delivered via both by immersion [27] or orally [25]. However, of those developed, one did not give impressive survival rates upon challenge [25] and the efficacy for the other was not investigated - although notably, with the latter, the antibody response to the vaccine was neither high nor consistent [27]. A common factor with both of these vaccines is that they are based on prokaryotic vectors. This may have important consequences with regard to correct folding and post-translational modifications of the viral antigens. Notably, the CyHV-3 antigens used were ORF149 [27] and ORF81 [25]. ORF149 is a glycoprotein [61], which may be dependent on post-translational modifications for correct folding. In the case of ORF149, only the fragment consisting of the $\mathrm{N}$-terminal cysteine-free domain was included in the vaccine, on the basis that it should not rely on post-translational modification [27], however the folding of the truncated versus non-truncated forms was not investigated. Conversely, the whole ORF81 gene was used in the other vector vaccine described [25]. While evidence indicates that ORF81 does not undergo extensive post-translational modification [62], it cannot be ruled out at this stage. In addition, in this case, CyHV-3 ORF81 was expressed as a fusion protein with SVCV gG, which may also have had an impact on correct folding [25]. Thus, the use of prokaryotic systems may have had important implications with regard to the efficacy of these bacterial vector vaccines when using viral antigens, and this aspect may need to be considered with any future CyHV-3 vector-antigen combinations. On this note, it was recently demonstrated that a eukaryotic vector system utilizing yeast (Pichia pastoris) could be used in the delivery of GFP to the epithelium and lamina propria of both the first and second intestine segments in common carp [63], indicating its potential use as part of new CyHV-3 vector vaccines. Furthermore, the same yeast species has also been used in the production of CyHV-2 subunit vaccine 
components and showed moderate-high survival rates in gibel carp [52].

\subsubsection{Antigen selection}

With regard to DNA, subunit and bacterial vector vaccine development, the choice of antigen is a crucial aspect. There have only been a few studies into immunological relevance of specific CyHV-3 proteins $[26,61,62,64]$ and they have arbitrarily focused on putative viral envelope and capsid proteins including ORF25, ORF65, ORF81, ORF84, ORF92, ORF99, ORF136, ORF138, ORF146, ORF148, and ORF149. These studies have had an important influence on the antigen choices made in the following vaccine studies [20-23,25,27]. However, CyHV-3 has a complex proteome with 34 structural virion proteins consistently detected $[2,24,49,65]$. Vaccine strategies may require the use of several different types of relevant viral antigen in order to induce sufficient protection. Thus, efforts to increase the amount of known immunologically relevant structural proteins will remain an important element in the future of CyHV-3 vaccine design. Furthermore, there may be many non-structural viral proteins that may be important in terms of major histocompatibility complex (MHC) Class I display to cytoxic T-cells as part of cell mediated adaptive immunity. The identification of such proteins may represent important steps towards the development of vaccines comprising viral antigens relevant to both major arms of the adaptive immune response.

\subsection{Future prospects on CyHV-3 vaccines based on whole viral particles}

\subsubsection{Inactivated vaccines}

CyHV-3 inactivated vaccine prototypes were intrinsically primed for mass vaccination using the oral route [30,31]. Both inactivated CyHV-3 vaccines described here utilize liposome encapsulation for oral delivery. While the results are encouraging, they also highlight some efficacy issues [30,31], however the use of adjuvants (see section 6.3) may help overcome this. In addition, other encapsulation methods used with other inactivated viral vaccines for example, PLGA encapsulation of inactivated viral haemorrhagic septicaemia virus (VHSV) for delivery to olive flounder, have also facilitated delivery and protection via both immersion and oral routes [66].

\subsubsection{Attenuated vaccines}

By far, the best performing CyHV-3 vaccines are the attenuated vaccines. Crucially these vaccines meet all of the three main criteria set out at the beginning of this section. Future research into CyHV-3 attenuated vaccines is likely to revolve around the identification of deletions that provide enhanced safety/efficacy profiles. There are two types of attenuated CyHV-3 vaccine: (i) conventional attenuated vaccine: designed empirically, through a combination of repeated serial passaging in vitro and UV irradiation [34] and (ii) recombinant attenuated vaccine: developed through rational mutagenesis of the viral genome associated with attenuation $[43,46]$. Both types were described in more detail in section 4 of this review. However, in terms of safety, the rationally designed vaccines are far superior for 3 key reasons. First, the determinism of the attenuation is known in the recombinant attenuated vaccines, but not in the conventional attenuated vaccine. While the conventional attenuated vaccine displays indels and point mutations, it is unclear which one(s) of them is (are) responsible for the attenuation. A single change in one crucial mutation for attenuation may cause reversion to virulence, making it difficult to conduct valid risk assessment on its use in the field. Secondly, the reversion of the rationally designed recombinant attenuated vaccines through recovery of an entire deleted gene is only possible by co-infection with a viral strain providing the missing gene, i.e. the same cells would need to be simultaneously infected with a wild type viral strain. Given the nature of the genetic changes responsible for attenuation, the chances of a rationally designed attenuated strain reverting to virulence are much lower. Thirdly, the absence of specific genes in the rationally designed strains greatly facilitates a more robust DIVA strategy, allowing surveillance and establishment of viral eradication plans. In summary, compared to conventional attenuated vaccine, the superior safety of the rationally designed vaccines is self-evident, and it is difficult to present convincing and rational argument to the contrary. Interestingly, the regulatory authorities in three countries have approved the use of the CyHV-3 conventional vaccine (USA, Indonesia and Israel) [15]. Given their superior safety, it is logical to conclude that such precedents should only act to strongly support the registration of recombinant attenuated vaccines that are currently under development. However, in some countries regulation authorities are still considering recombinant attenuated vaccines as genetically modified organisms and apply more restrictive rules for registration.

\subsection{Mucosal immunity and future prospects for the study of the immune response induced by vaccines}

As the evidence indicates above, a push towards oral and immersion delivery will be a crucial part of the future direction of CyHV-3 vaccines. Not only is this more compatible with mass vaccination, it also facilitates entry and/or immune stimulation at mucosal surfaces. Mucosa-associated tissues of teleost fish such as skin, gills and intestine play crucial roles in protection against pathogens [43,67-69]. Thus, the central aim of teleost vaccination should ideally be to induce mucosal immunity in one or more mucosal surface(s) (i.e. gut, skin, gills) leading to subsequent stimulation of a systemic protection across all mucosal barriers. This makes oral or immersion delivery, an attractive option for any fish vaccine. However, the occurrence of tolerance on mucosal surfaces may be an obstacle, particularly where repeat/boost vaccination regimes are necessary. The ability to gain tolerance at mucosal surfaces is important in avoiding immune reactions to beneficial commensals [68]. Mucosal vaccination could in some circumstances also induce tolerance against the vaccine antigens. This phenomenon has been demonstrated for the gut mucosa after oral delivery of antigens [60], including in carp [70]. This is referred to as "oral tolerance", and while it may not be unique to the gut, an equivalent phenomenon has not been yet described with other fish mucosal surfaces, indicating that the gut mucosal surfaces are possibly more prone to this. Finally, the oral route has one additional drawback. The dose of vaccine received by each fish depends on its appetite and so is not homogeneous between all fish, which may of course affect efficacy results.

This suggests that immersion-based delivery may be less problematic. Of the vaccine formats described, attenuated CyHV-3 vaccines are the most suited to immersion-based delivery. The skin of carp has been shown to act as the major portal of entry for CyHV-3 wild type virus and the $\Delta 56-57$ recombinant vaccine [43]. Moreover, it was demonstrated that the skin is the major site of viral replication of the attenuated strain following vaccination by immersion in water containing the virus. It is likely that the replication and immune stimulation at this important mucosal surface ultimately explains the protection observed against subsequent viral challenge [43]. Interestingly, CyHV-3 was also shown to infect carp through infection of the periodontal pharyngeal mucosa when administered through contaminated food pellets [71]. Therefore, it may be feasible to also deliver this $\Delta 56-57$ recombinant attenuated vaccine via the oral route through ingestion of spiked food pellet. Thus, this attenuated strain may also represent an important research tool, providing an opportunity to investigate immune responses to a recombinant attenuated vaccine at multiple mucosal surfaces.

\subsection{Future prospects on use of adjuvants}

The use of adjuvants may also be a key feature in increasing the efficacy of CyHV-3 vaccines. To date, their inclusion in CyHV-3 experimental vaccine formulation has been limited and has shown no real success [22,32]. However, vaccines developed against other fish 
pathogens have included immunostimulants such as beta-glucans, polyinosinic polycytidylic acid (poly I:C), CpG [72], many of which may be tested and exploited in future experimental CyHV-3 vaccines. The choice of adjuvant is known to have a significant impact on vaccine performance [73], not only by simply enhancing the immune response, but also by guiding the type of adaptive response that should be developed $[74,75]$. Like viruses of other vertebrates, complete clearance of CyHV-3 may also rely on the polarization towards T-helper-1 (Th1) response, although this still needs to be fully investigated. As knowledge grows, future adjuvant selection for CyHV-3 vaccines may be based on those known to stimulate the appropriate adaptive immune response. Getting to this point will also require the generation of more data on specific cytokine profiles displayed by carp in response to a range of different adjuvants, and thus this represents a key field or research for future development.

\subsection{Future prospects on CyHV-3 vaccine testing and harmonization}

In CyHV-3 vaccine studies described in this review, there are a variety of wild type viral strains used and ways in which carp are challenged with those viral strains after vaccination. These include: (i) direct application of virus to gills [30,31], (ii) IP injection [20-22,32], (iii) bath/immersion [23,33,36,46], (iv) feeding/oral [25], and (v) cohabitation with clinically infected fish $[14,23,34,43]$. Out of these methods, cohabitation is the most representative of a natural infection and may be the most valid form of challenge post-vaccination. However, some critics and concerns can be raised against this method of challenge. First, the variability of virus excretion by shedder fish could be the source of experimental variabilities. Second, this approach requires additional subjects for which the application of ending points is problematic leading to ethics concerns. Of note, challenge through bath/immersion and cohabitation have been shown to reveal different levels of protection [23]. In the quoted study, protection was only observed after immersion challenge but not after cohabitation. Therefore, in order to derive meaningful conclusions, where possible, it may be prudent for future CyHV-3 vaccine studies to include cohabitation challenge as part of the experimental design.

\section{Conclusion}

We can learn a lot from the studies that have been conducted into the development of CyHV-3 vaccines. However, currently there are certain knowledge gaps in terms of antigen selection, delivery mechanisms and adjuvant impact. Thus, there is tremendous scope for new innovation in the design, application and enhancement of CyHV-3 vaccines. Continued scientific progression and expansion of knowledge together with continued engagement with authorities on appropriate regulatory framework are aspects that will be instrumental in controlling the economic impact of this devastating virus.

\section{Acknowledgements and funding}

YG is a research fellow of the Chinese Scholarship Council. OD is a Marie Curie research fellow (European Union). This work was supported by the University of Liège (ARC15/19-12) and the FNRS (CDR J.0094.15 and PDR T.0241.19). The laboratory of Immunology and Vaccinology has been deeply involved in the rational development of a recombinant attenuated vaccine against CyHV-3.

\section{References}

[1] F.A.O., The State of World Fisheries and Aquaculture 2018, (2018).

[2] M. Boutier, M. Ronsmans, K. Rakus, J. Jazowiecka-Rakus, C. Vancsok, L. Morvan, M.M.D. Peñaranda, D.M. Stone, K. Way, S.J. van Beurden, A.J. Davison, A. Vanderplasschen, Chapter three - cyprinid herpesvirus 3: an archetype of fish alloherpesviruses, in: K.M. Margaret Kielian, C.M. Thomas (Eds.), Advances in Virus Research, Academic Press, 2015, pp. 161-256.
[3] M. Ilouze, A. Dishon, M. Kotler, Characterization of a novel virus causing a lethal disease in carp and koi, Microbiol. Mol. Biol. Rev. 70 (1) (2006) 147-156.

[4] World-Organisation-for-Animal-Health, Chapter 2.3.6. Koi Herpesvirus Disease, Manual Of Diagnostic Tests For Aquatic Animals 20122012, pp. 328-344.

[5] World-Organisation-for-Animal-Health, OIE-Listed diseases, Infections and Infestations in Force in 2019, (2019) accessed 17/07/2019.2019 http://www.oie. int/en/animal-health-in-the-world/oie-listed-diseases-2019.

[6] A. Ronen, A. Perelberg, J. Abramowitz, M. Hutoran, S. Tinman, I. Bejerano, M. Steinitz, M. Kotler, Efficient vaccine against the virus causing a lethal disease in cultured Cyprinus carpio, Vaccine 21 (32) (2003) 4677-4684.

[7] A.N. Reed, S. Izume, B.P. Dolan, S. LaPatra, M. Kent, J. Dong, L. Jin, Identification of B cells as a major site for cyprinid herpesvirus 3 latency, J. Virol. 88 (16) (2014) 9297-9309.

[8] K. Rakus, M. Ronsmans, M. Forlenza, M. Boutier, M.C. Piazzon, J. JazowieckaRakus, D. Gatherer, A. Athanasiadis, F. Farnir, A.J. Davison, P. Boudinot, T. Michiels, G.F. Wiegertjes, A. Vanderplasschen, Conserved fever pathways across vertebrates: a herpesvirus expressed decoy TNF-alpha receptor delays behavioral fever in fish, Cell Host Microbe 21 (2) (2017) 244-253.

[9] T. Aoki, I. Hirono, K. Kurokawa, H. Fukuda, R. Nahary, A. Eldar, A.J. Davison, T.B. Waltzek, H. Bercovier, R.P. Hedrick, Genome sequences of three koi herpesvirus isolates representing the expanding distribution of an emerging disease threatening koi and common carp worldwide, J. Virol. 81 (10) (2007) 5058-5065.

[10] W. Li, X. Lee, S. Weng, J. He, C. Dong, Whole-genome sequence of a novel Chinese cyprinid herpesvirus 3 isolate reveals the existence of a distinct European genotype in East Asia, Vet. Microbiol. 175 (2-4) (2015) 185-194.

[11] Y. Gao, N.M. Suarez, G.S. Wilkie, C. Dong, S. Bergmann, P.A. Lee, A.J. Davison, A.F.C. Vanderplasschen, M. Boutier, Genomic and biologic comparisons of cyprinid herpesvirus 3 strains, Vet. Res. 49 (1) (2018) 40.

[12] S. Hammoumi, T. Vallaeys, A. Santika, P. Leleux, E. Borzym, C. Klopp, J.C. Avarre, Targeted genomic enrichment and sequencing of CyHV-3 from carp tissues confirms low nucleotide diversity and mixed genotype infections, PeerJ 4 (2016) e2516.

[13] A. Mletzko, A. Amtmann, S. Bergmann, P. Lee, J. Christian, R. Buchholz, A. Becker, Inoculation of cyprinid herpesvirus 3 (CyHV-3) on common carp brain cells-influence of process parameters on virus yield, In Vitro Cell. Dev. Biol. Anim. 53 (7) (2017) 579-585.

[14] M. Boutier, Y. Gao, C. Vancsok, N.M. Suarez, A.J. Davison, A. Vanderplasschen, Identification of an essential virulence gene of cyprinid herpesvirus 3, Antivir. Res. 145 (2017) 60-69.

[15] A. Dishon, O. Ashoulin, E. Scott Weber Iii, M. Kotler, Vaccination against koi herpesvirus disease, in: R. Gudding, A. Lillehaug, $\varnothing$. Evensen (Eds.), Fish Vaccination, John Wiley \& Sons Ltd, 2014, pp. 321-333.

[16] A. Baumer, M. Fabian, M.R. Wilkens, D. Steinhagen, M. Runge, Epidemiology of cyprinid herpesvirus-3 infection in latently infected carp from aquaculture, Dis. Aquat. Org. 105 (2) (2013) 101-108.

[17] T. Minamoto, M.N. Honjo, H. Yamanaka, K. Uchii, Z. Kawabata, Nationwide Cyprinid herpesvirus 3 contamination in natural rivers of Japan, Res. Vet. Sci. 93 (1) (2012) 508-514.

[18] K. Uchii, T. Minamoto, M.N. Honjo, Z. Kawabata, Seasonal reactivation enables Cyprinid herpesvirus 3 to persist in a wild host population, FEMS Microbiol. Ecol. 87 (2) (2014) 536-542.

[19] L.B. Holvold, A.I. Myhr, R.A. Dalmo, Strategies and hurdles using DNA vaccines to fish, Vet. Res. 45 (1) (2014) 21.

[20] J. Zhou, J. Xue, Q. Wang, X. Zhu, X. Li, W. Lv, D. Zhang, Vaccination of plasmid DNA encoding ORF81 gene of CJ strains of KHV provides protection to immunized carp, In Vitro Cell. Dev. Biol. Anim. 50 (6) (2014) 489-495.

[21] J.X. Zhou, H. Wang, X.W. Li, X. Zhu, W.L. Lu, D.M. Zhang, Construction of KHV-CJ ORF25 DNA vaccine and immune challenge test, J. Fish Dis. 37 (4) (2014) 319-325.

[22] L. Liu, S. Gao, W. Luan, J. Zhou, H. Wang, Generation and functional evaluation of a DNA vaccine co-expressing Cyprinid herpesvirus-3 envelope protein and carp interleukin-1 beta, Fish Shellfish Immunol. 80 (2018) 223-231.

[23] C.W.E. Embregts, R. Tadmor-Levi, T. Vesely, D. Pokorova, L. David, G.F. Wiegertjes, M. Forlenza, Intra-muscular and oral vaccination using a Koi Herpesvirus ORF25 DNA vaccine does not confer protection in common carp (Cyprinus carpio L.), Fish Shellfish Immunol. 85 (2019) 90-98.

[24] C. Vancsok, M.M.D. Penaranda, V.S. Raj, B. Leroy, J. Jazowiecka-Rakus, M. Boutier, Y. Gao, G.S. Wilkie, N.M. Suarez, R. Wattiez, L. Gillet, A.J. Davison, A.F.C. Vanderplasschen, Proteomic and functional analyses of the virion transmembrane proteome of cyprinid herpesvirus 3, J. Virol. 91 (21) (2017).

[25] L.C. Cui, X.T. Guan, Z.M. Liu, C.Y. Tian, Y.G. Xu, Recombinant lactobacillus expressing G protein of spring viremia of carp virus (SVCV) combined with ORF81 protein of koi herpesvirus (KHV): a promising way to induce protective immunity against SVCV and KHV infection in cyprinid fish via oral vaccination, Vaccine 33 (27) (2015) 3092-3099.

[26] F. Torrent, A. Villena, P.A. Lee, W. Fuchs, S.M. Bergmann, J.M. Coll, The aminoterminal domain of ORF149 of koi herpesvirus is preferentially targeted by IgM from carp populations surviving infection, Arch. Virol. 161 (10) (2016) 2653-2665.

[27] J. Coll, Fish mass immunization against virus with recombinant "spiny" bacterins, Fish Shellfish Immunol. 67 (2017) 393-401.

[28] H.M. Munang'andu, S. Mutoloki, $\varnothing$. Evensen, Non-replicating vaccines, in: R. Gudding, A. Lillehaug, Ø. Evensen (Eds.), Fish Vaccination, John Wiley \& Sons Ltd, 2014, pp. 22-32.

[29] I. Sommerset, B. Krossoy, E. Biering, P. Frost, Vaccines for fish in aquaculture, Expert Rev. Vaccines 4 (1) (2005) 89-101.

[30] S. Yasumoto, Y. Kuzuya, M. Yasuda, T. Yoshimura, T. Miyazaki, Oral immunization of common carp with a liposome vaccine fusing koi herpesvirus antigen, Fish Pathol. 41 (4) (2006) 141-145. 
[31] T. Miyazaki, S. Yasumoto, Y. Kuzuya, T. Yoshimura, A Primary Study On Oral Vaccination With Liposomes Entrapping Koi Herpesvirus (Khv) Antigens Against Khv Infection In Carp, Diseases In Asian Aquaculture, Colombo, Sri Lanka, 2005, pp. 99-104.

[32] T. Schmid, L. Gaede, K. Bottcher, G. Brauer, D. Fichtner, R. Beckmann, S. Speck, F. Becker, U. Truyen, Efficacy assessment of three inactivated koi herpes virus antigen preparations against experimental challenge virus infection in common carp, J. Fish Dis. 39 (8) (2016) 1007-1013.

[33] M.R. O'Connor, T.B. Farver, K.V. Malm, S.C. Yun, G.D. Marty, K. Salonius, A. Dishon, E.P. Weber 3rd, Protective immunity of a modified-live cyprinid herpesvirus 3 vaccine in koi (Cyprinus carpio koi) 13 months after vaccination, Am. J. Vet. Res. 75 (10) (2014) 905-911.

[34] A. Perelberg, A. Ronen, M. Hutoran, Y. Smith, M. Kotler, Protection of cultured Cyprinus carpio against a lethal viral disease by an attenuated virus vaccine, Vaccine 23 (26) (2005) 3396-3403.

[35] A. Perelberg, M. Ilouze, M. Kotler, M. Steinitz, Antibody response and resistance of Cyprinus carpio immunized with cyprinid herpes virus 3 (CyHV-3), Vaccine 26 (29-30) (2008) 3750-3756.

[36] E.P. Weber 3rd, K.V. Malm, S.C. Yun, L.A. Campbell, P.H. Kass, G.D. Marty, K. Salonius, A. Dishon, Efficacy and safety of a modified-live cyprinid herpesvirus 3 vaccine in koi (Cyprinus carpio koi) for prevention of koi herpesvirus disease, Am. J. Vet. Res. 75 (10) (2014) 899-904.

[37] T. Zak, A. Perelberg, I. Magen, A. Milstein, D. Joseph, Heterosis in the growth rate of Hungarian-Israeli common carp crossbreeds and evaluation of their sensitivity to koi herpes virus (KHV) disease, Isr. J. Aquacult. Bamidgeh 59 (2) (2007) 63-72.

[38] E.N. Meeusen, J. Walker, A. Peters, P.P. Pastoret, G. Jungersen, Current status of veterinary vaccines, Clin. Microbiol. Rev. 20 (3) (2007) 489-510.

[39] R.P. Hedrick, T.B. Waltzek, T.S. McDowell, Susceptibility of koi carp, common carp, goldfish, and goldfish $\times$ common carp hybrids to cyprinid herpesvirus- 2 and herpesvirus-3, J. Aquat. Anim. Health 18 (1) (2006) 26-34.

[40] R.K. Kopf, M. Boutier, C.M. Finlayson, K. Hodges, P. Humphries, A. King, R.T. Kingsford, J. Marshall, H.M. McGinness, R. Thresher, A. Vanderplasschen, Biocontrol in Australia: can a carp herpesvirus (CyHV-3) deliver safe and effective ecological restoration? Biol. Invasions 21 (6) (2019) 1857-1870.

[41] K.A. McColl, A. Sunarto, J. Slater, K. Bell, M. Asmus, W. Fulton, K. Hall, P. Brown, D. Gilligan, J. Hoad, L.M. Williams, M.S.J. Crane, Cyprinid herpesvirus 3 as a potential biological control agent for carp (Cyprinus carpio) in Australia: susceptibility of non-target species, J. Fish Dis. 40 (9) (2017) 1141-1153.

[42] B. Costes, G. Fournier, B. Michel, C. Delforge, V.S. Raj, B. Dewals, L. Gillet, P. Drion, A. Body, F. Schynts, F. Lieffrig, A. Vanderplasschen, Cloning of the koi herpesvirus genome as an infectious bacterial artificial chromosome demonstrates that disruption of the thymidine kinase locus induces partial attenuation in Cyprinus carpio koi, J. Virol. 82 (10) (2008) 4955-4964.

[43] M. Boutier, M. Ronsmans, P. Ouyang, G. Fournier, A. Reschner, K. Rakus, G.S. Wilkie, F. Farnir, C. Bayrou, F. Lieffrig, H. Li, D. Desmecht, A.J. Davison, A. Vanderplasschen, Rational development of an attenuated recombinant cyprinid herpesvirus 3 vaccine using prokaryotic mutagenesis and in vivo bioluminescent imaging, PLoS Pathog. 11 (2) (2015) e1004690.

[44] W. Fuchs, D. Fichtner, S.M. Bergmann, T.C. Mettenleiter, Generation and characterization of koi herpesvirus recombinants lacking viral enzymes of nucleotide metabolism, Arch. Virol. 156 (6) (2011) 1059-1063.

[45] R.P. Hedrick, O. Gilad, S. Yun, J.V. Spangenberg, G.D. Marty, R.W. Nordhausen, M.J. Kebus, H. Bercovier, A. Eldar, A herpesvirus associated with mass mortality of juvenile and adult koi, a strain of common carp, J. Aquat. Anim. Health 12 (1) (2000) 44-57.

[46] L. Schroder, S. Klafack, S.M. Bergmann, D. Fichtner, Y. Jin, P.Y. Lee, D. Hoper, T.C. Mettenleiter, W. Fuchs, Generation of a potential koi herpesvirus live vaccine by simultaneous deletion of the viral thymidine kinase and dUTPase genes, J. Gen. Virol. 100 (4) (2019) 642-655.

[47] L. Schröder, S. Klafack, S.M. Bergmann, P.-Y.A. Lee, K. Franzke, D. Höper, T.C. Mettenleiter, W. Fuchs, Characterization of gene deletion mutants of Cyprinid herpesvirus 3 (koi herpesvirus) lacking the immunogenic envelope glycoproteins pORF25, pORF65, pORF148 and pORF149, Virus Res. 261 (2019) 21-30.

[48] M. Ronsmans, M. Boutier, K. Rakus, F. Farnir, D. Desmecht, F. Ectors, M. Vandecan, F. Lieffrig, C. Melard, A. Vanderplasschen, Sensitivity and permissivity of Cyprinus carpio to cyprinid herpesvirus 3 during the early stages of its development: importance of the epidermal mucus as an innate immune barrier, Vet. Res. 45 (1) (2014) 100 .

[49] B. Michel, B. Leroy, V. Stalin Raj, F. Lieffrig, J. Mast, R. Wattiez, A.F. Vanderplasschen, B. Costes, The genome of cyprinid herpesvirus 3 encodes 40 proteins incorporated in mature virions, J. Gen. Virol. 91 (Pt 2) (2010) 452-462.

[50] T. Ito, Y. Maeno, Effect of booster shot and investigation of vaccination efficacy period against herpesviral haematopoietic necrosis (HVHN) in goldfish Carassius auratus, Vet. Microbiol. 175 (1) (2015) 139-144.

[51] L. Zhang, J. Ma, Y. Fan, Y. Zhou, J. Xu, W. Liu, Z. Gu, L. Zeng, Immune response and protection in gibel carp, Carassius gibelio, after vaccination with beta-propiolactone inactivated cyprinid herpesvirus 2, Fish Shellfish Immunol. 49 (2016) 344-350.

[52] Y. Zhou, N. Jiang, J. Ma, Y. Fan, L. Zhang, J. Xu, L. Zeng, Protective immunity in gibel carp, Carassius gibelio of the truncated proteins of cyprinid herpesvirus 2 expressed in Pichia pastoris, Fish Shellfish Immunol. 47 (2) (2015) 1024-1031.

[53] K.E. Nusbaum, B.F. Smith, P. DeInnocentes, R.C. Bird, Protective immunity induced by DNA vaccination of channel catfish with early and late transcripts of the channel catfish herpesvirus (IHV-1), Vet. Immunol. Immunopathol. 84 (3-4) (2002) $151-168$.

[54] H. Harbottle, K.P. Plant, R.L. Thune, DNA vaccination against channel catfish virus results in minimal immune response and is not efficacious against challenge, J. Aquat. Anim. Health 17 (3) (2005) 251-262.

[55] E.J. Noga, J.X. Hartmann, Establishment of walking catfish (Clarias batrachus) cell lines and development of a channel catfish (Ictalurus punctatus) virus vaccine, Can. J. Fish. Aquat. Sci. 38 (8) (1981) 925-930.

[56] N. Vanderheijden, P. Alard, C. Lecomte, J.A. Martial, The attenuated V60 strain of channel catfish virus possesses a deletion in ORF50 coding for a potentially secreted glycoprotein, Virology 218 (2) (1996) 422-426.

[57] H.G. Zhang, L.A. Hanson, Deletion of thymidine kinase gene attenuates channel catfish herpesvirus while maintaining infectivity, Virology 209 (2) (1995) 658-663.

[58] D. Kunec, L.A. Hanson, S. van Haren, I.F. Nieuwenhuizen, S.C. Burgess, An overlapping bacterial artificial chromosome system that generates vectorless progeny for channel catfish herpesvirus, J. Virol. 82 (8) (2008) 3872-3881.

[59] S. Vimal, S. Abdul Majeed, K.S.N. Nambi, N. Madan, M.A. Farook, C. Venkatesan, G. Taju, S. Venu, R. Subburaj, A.R. Thirunavukkarasu, A.S. Sahul Hameed, Delivery of DNA vaccine using chitosan-tripolyphosphate (CS/TPP) nanoparticles in Asian sea bass, Lates calcarifer (Bloch, 1790) for protection against nodavirus infection, Aquaculture 420-421 (2014) 240-246.

[60] C.W. Embregts, M. Forlenza, Oral vaccination of fish: lessons from humans and veterinary species, Dev. Comp. Immunol. 64 (2016) 118-137.

[61] W. Fuchs, H. Granzow, M. Dauber, D. Fichtner, T.C. Mettenleiter, Identification of structural proteins of koi herpesvirus, Arch. Virol. 159 (12) (2014) 3257-3268.

[62] D. Rosenkranz, B.G. Klupp, J.P. Teifke, H. Granzow, D. Fichtner, T.C. Mettenleiter, W. Fuchs, Identification of envelope protein pORF81 of koi herpesvirus, J. Gen. Virol. 89 (Pt 4) (2008) 896-900.

[63] C.W.E. Embregts, F. Reyes-Lopez, A.C. Pall, A. Stratmann, L. Tort, N. Lorenzen, K. Engell-Sorensen, G.F. Wiegertjes, M. Forlenza, J.O. Sunyer, D. Parra, Pichia pastoris yeast as a vehicle for oral vaccination of larval and adult teleosts, Fish Shellfish Immunol. 85 (2019) 52-60.

[64] S.J. Monaghan, K.D. Thompson, J.E. Bron, S.M. Bergmann, T.S. Jung, T. Aoki, K.F. Muir, M. Dauber, S. Reiche, D. Chee, S.M. Chong, J. Chen, A. Adams, Expression of immunogenic structural proteins of cyprinid herpesvirus 3 in vitro assessed using immunofluorescence, Vet. Res. 47 (1) (2016) 8.

[65] Y. Yi, H. Zhang, X. Lee, S. Weng, J. He, C. Dong, Extracellular virion proteins of two Chinese CyHV-3/KHV isolates, and identification of two novel envelope proteins, Virus Res. 191 (2014) 108-116.

[66] S. Kole, S.S.N. Qadiri, S.M. Shin, W.S. Kim, J. Lee, S.J. Jung, PLGA encapsulated inactivated-viral vaccine: formulation and evaluation of its protective efficacy against viral haemorrhagic septicaemia virus (VHSV) infection in olive flounder (Paralichthys olivaceus) vaccinated by mucosal delivery routes, Vaccine 37 (7) (2019) 973-983.

[67] B. Costes, V.S. Raj, B. Michel, G. Fournier, M. Thirion, L. Gillet, J. Mast, F. Lieffrig, M. Bremont, A. Vanderplasschen, The major portal of entry of koi herpesvirus in Cyprinus carpio is the skin, J. Virol. 83 (7) (2009) 2819-2830.

[68] D. Gomez, J.O. Sunyer, I. Salinas, The mucosal immune system of fish: the evolution of tolerating commensals while fighting pathogens, Fish Shellfish Immunol. 35 (6) (2013) 1729-1739.

[69] I. Salinas, The mucosal immune system of teleost fish, Biology 4 (3) (2015) $525-539$.

[70] P.H. Joosten, M.Y. Engelsma, M.D. van der Zee, J.H. Rombout, Induction of oral tolerance in carp (Cyprinus carpio L.) after feeding protein antigens, Vet. Immunol. Immunopathol. 60 (1-2) (1997) 187-196.

[71] G. Fournier, M. Boutier, V. Stalin Raj, J. Mast, E. Parmentier, P. Vanderwalle, D. Peeters, F. Lieffrig, F. Farnir, L. Gillet, A. Vanderplasschen, Feeding Cyprinus carpio with infectious materials mediates cyprinid herpesvirus 3 entry through infection of pharyngeal periodontal mucosa, Vet. Res. 43 (2012) 6.

[72] J. Bøgwald, R.A. Dalmo, 10 - developments in adjuvants for fish vaccines, in: B. Austin (Ed.), Infectious Disease in Aquaculture, Woodhead Publishing, 2012, pp. 244-274.

[73] H.L. Thim, S. Villoing, M. McLoughlin, K.E. Christie, S. Grove, P. Frost, J.B. Jorgensen, Vaccine adjuvants in fish vaccines make a difference: comparing three adjuvants (montanide ISA763A oil, CpG/poly I:C combo and VHSV glycoprotein) alone or in combination formulated with an inactivated whole salmonid alphavirus antigen, Vaccines (Basel) 2 (2) (2014) 228-251.

[74] K.S. Korsholm, R.V. Petersen, E.M. Agger, P. Andersen, T-helper 1 and T-helper 2 adjuvants induce distinct differences in the magnitude, quality and kinetics of the early inflammatory response at the site of injection, Immunology 129 (1) (2010) 75-86.

[75] C. Tafalla, J. Bogwald, R.A. Dalmo, Adjuvants and immunostimulants in fish vaccines: current knowledge and future perspectives, Fish Shellfish Immunol. 35 (6) (2013) 1740-1750. 